\title{
IMPACT OF NITROGEN REGIME ON FATTY ACID PROFILES OF DESMODESMUS QUADRICAUDATUS AND CHLORELLA SP. AND ABILITY TO PRODUCE BIOFUEL
}

\author{
H. M. Shafik ${ }^{1,2 *}$, M. G. SAAD ${ }^{1}$ and H. A. El-Serehy ${ }^{3}$ \\ ${ }^{1}$ Botany Department, Faculty of Science, Port-Said University, Port-Said 42536, Egypt \\ E-mail:drmgs84@yahoo.com \\ ${ }^{2}$ MTA-PE, Limnoecological Research Group, Hungarian Academy of Sciences \\ University of Pannonia, H-8200 Veszprém, Egyetem u. 10, Hungary \\ E-mails: heshamshafik@aloms.uni-pannon.hu, *heshamshafik@yahoo.co.uk \\ ${ }^{3}$ College of Science, King Saud University, Riyadh 11451, P. O. Box 2455, Saudi Arabia \\ E-mail: helserehy@ksu.edu.sa
}

(Received 8 September, 2014; Accepted 15 December, 2014)

Microalgae have emerged as one of the most promising sources for fatty acid production. Since the various fatty acid profiles (chain length, degree of unsaturation, and branching of the chain) of the different sources influence biodiesel fuel properties, it is important to possess data on how the presence of $\mathrm{NaNO}_{3}$ as nitrogen source can influence the profile of produced fatty acids from algae. The fatty acid profiles of Desmodesmus quadricaudatus and Chlorella sp. were detected in pure batch cultures experiments. BG-11 nitrogen free medium and the medium contained $1.5 \mathrm{~g} \mathrm{NaNO}_{3} \mathrm{l}^{-1}$ were used in this investigation. At late stationary growth phase in nitrogen free medium, Chlorella sp. produced $58.39 \%$ saturated fatty acids and $41.60 \%$ unsaturated fatty acids. While in medium contained $1.5 \mathrm{~g} \mathrm{NaNO}_{3} \mathrm{l}^{-1}$ Chlorella sp. produced $62.08 \%$ saturated fatty acids and $37.92 \%$ unsaturated fatty acids. In nitrogen free medium D. quadricaudatus produced $66.92 \%$ saturated fatty acids and $33.07 \%$ unsaturated fatty acids. While in cultures contained $1.5 \mathrm{~g} \mathrm{NaNO}_{3} \mathrm{l}^{-1}$ D. quadricaudatus produced $51.62 \%$ saturated fatty acids and $48.37 \%$ unsaturated fatty acids.

The fatty acid profile of Chlorella sp. and D. quadricaudatus that isolated from Egyptian water body and grown in nitrogen free medium may be suitable for biodiesel production. The results discussed and compared to fatty acid profiles produced by other algal species.

Key words: batch cultures, Chlorella sp., Desmodesmus quadricaudatus, fatty acid, nitrogen regime, biodiesel

\section{INTRODUCTION}

Microalgae have significant environmental and commercial importance. They are not only sources of food for humans and animals, but are also the sources of a wide range of chemical compounds used in industry, food tech- 
nology and pharmaceuticals. They are microscopic, photosynthetic renewable resources with the potential to produce large quantities of lipids (fats and oils). Hossain et al. (2008) stated that it is very simple to extract oil from algae.

Many microalgae have high photosynthetic efficiency, fast growth rate, high biomass productivities and highest $\mathrm{CO}_{2}$ fixation and $\mathrm{O}_{2}$ production rate. Also, it can be grown in variable climates, non-arable land including marginal areas unsuitable for agricultural purpose, no seasonal production, thrive in nonportable water, use less water and do not compete with food crop culture. Many microalgae are capable of accumulating a large amount of lipids in the cells (Sheehan et al. 1998). On average, the lipid contents typically range from $10 \%$ to $30 \%$ of dry weight. Algae grown to late logarithmic growth phase typically contain $30-40 \%$ proteins, $10-20 \%$ lipids and $5-15 \%$ carbohydrates (Barsanti and Gualtieri 2006). Mata et al. (2010) showed that depending on the specific algae species and their cultivation conditions, however, microalgal lipid production might range widely from $2 \%$ to $75 \%$. In some extreme cases, it can reach $70-90 \%$ of dry weight (Chisti 2007, Li et al. 2008). Nitrate and silicate stress has effect on the lipid content in a variety of phytoplankton (Shifrin and Chisholm 1981). Illman et al. (2000) studied five strains of the green alga Chlorella, and reported an increase in lipid content in all five strains when grown in low-nitrogen media. In the case of Chlorella emersonii and C. minutissima, $63 \%$ and $56 \%$ oil were obtained in low-nitrogen media compared to $29 \%$ and $31 \%$ in high-nitrogen media, respectively. Scragg et al. (2002) supported these findings by also finding that the lipid content increased in low-N medium for Chlorella strains.

Dayananda et al. (2007) illustrated that the content of lipid, carbohydrate and proteins varies from species to species. Most common algae like Botryococcus braunii, Chlorella, Crypthecodinium, Cylindrotheca, Dunaliella, Isochrysis, Nannochloris, Nannochloropsis, Neochloris, Nitzschia, Phaeodactylum, Porphyridium, Schizochytrium, Scenedesmus and Tetraselmis species have oil levels between $20 \%$ and $50 \%$, but higher productivities can be reached. Under adverse growth conditions, such as nitrogen limitation, low temperature, high light intensity, high salt concentration and high iron concentration the lipid content in some of micro-algae increased (Hsieh and $\mathrm{Wu} 2009$ ). This may be due to alteration in their lipid biosynthesis pathways towards the formation and accumulation of neutral lipids (Hu et al. 2008). Lipid accumulation was up to $80 \%$ of dry cell weight and mainly in the form of tri-acyl-glycerol due to the shift in metabolism from membrane lipid synthesis to the storage of neutral lipids tri-acyl-glycerides (TAG). Paulson and Ginder (2007) concluded that algal lipids occur in cells predominantly as either polar lipids (mostly in membranes) or lipid bodies, typically in the form of tri-acyl-glycerides (TAG). The latter are accumulated in large amounts during photosynthesis as a mechanism to endure adverse environmental conditions. Polar lipids usually contain polyunsaturated fatty acids (PUFA), which are long-chained, but have 
good fluidity properties. TAG in lipid storage bodies typically contain mostly saturated fatty acids (SFA) that have high-energy contents, but, depending on the fatty acid profile of the algal strain, may lack fluidity under cold conditions. Provided the algal oil is low enough in moisture and free fatty acids, biodiesel is typically produced from TAG with methanol using base-catalysed transesterification (Schuchard et al. 1998). Fatty acids are converted as source of energy. The idea of using microalgae as a source of fatty acids, which may be changed to fuel is not new (Kapdan and Kargi 2006, Meier 1955). Changing of fatty acids to fatty acid alkyl esters, fatty acid methyl esters (FAME), or long-chain mono alkyl esters are the main key for biodiesel production from algae (Thomas 2006). Triglycerides in oil are transesterificated with a lower alcohol in the presence of an acidic or a basic catalyst into the corresponding long-chain fatty acid alkyl esters (Tyagi et al. 2010).

The accumulation of lipid begins as the cells enter stationary phase and cell division ceases; the timing of this event would be different for individual cells within a population. Nutrient limitation, generally nitrate or silica, can trigger lipid accumulation in microalgae. Nutrient deprivation can cause a decrease in cell division, which presumably results in "targeting" of excess fixed carbon into storage lipids. In green algae, lipid accumulation is induced among others by $\mathrm{N}$ starvation. $\mathrm{N}$ is a component of many cellular molecules, and $\mathrm{N}$ limitation would induce a complex response, affecting photosynthesis, protein and nucleic acid synthesis, and other biochemical processes (Sheehan et al. 1998). Shafik $(1991,2003)$ and Kenesi et al. (2009) studied the effect of nitrogen forms and its concentration on growth rate, cell composition and morphology of some green and prokaryotic algae.

This study aimed to show the effects of absence and presence of nitrogen on fatty acid profiles produced by Chlorella sp. and Desmodesmus quadricaudatus isolated from Egyptian water. Moreover, to compare the fatty acids profiles of the studied species to that used for biofuel production in some literature.

\section{MATERIALS AND METHODS}

\section{Isolation and identification of algal strains}

Microalgae samples were collected from variety of freshwater bodies at Port-Said City in summer 2009. Chlorella sp. and Desmodesmus quadricaudatus (Turpin) Hegewald (this name is currently regarded as a synonym of Scenedesmus quadricauda (Turpin) Brébisson) were isolated from these samples. Initial strain isolations were performed by streaking out samples onto $1.5 \%$ agar plates containing BG-11 medium. Each strain was examined using binocular light microscopy (SME-F4D, Rating: $85 \mathrm{~V}$ to $265 \mathrm{~V}, 50 / 60 \mathrm{~Hz}$, Halogen lamp: 
$60 \mathrm{~V} 20 \mathrm{~W}$, Delay-action fuse: 1 A) to look for morphological differences and to confirm identification of isolated algal strains according to Smith (2010).

\section{Cultivation and experiment design}

The used BG-11 medium contained $\left(\mathrm{g} \mathrm{l}^{-1}\right), \mathrm{NaNO}_{3^{\prime}}, 1.5 ; \mathrm{K}_{2} \mathrm{HPO}_{4} \cdot 3 \mathrm{H}_{2} \mathrm{O}$, $0.04 ; \mathrm{MgSO}_{4} \cdot 7 \mathrm{H}_{2} \mathrm{O}, 0.075 ; \mathrm{CaCl}_{2} \cdot 2 \mathrm{H}_{2} \mathrm{O}, 0.036$; citric acid, 0.006, ferric ammonium citrate, $0.006 ; \mathrm{Na}_{2} \mathrm{EDTA}, 0.001 ; \mathrm{Na}_{2} \mathrm{CO}_{3^{\prime}}$ 0.02. In addition to $1 \mathrm{ml}$ of trace metal solution (including $\mathrm{H}_{3} \mathrm{BO}_{3}, 2.86 \mathrm{~g} ; \mathrm{MnCl}_{2} \cdot 4 \mathrm{H}_{2} \mathrm{O}, 1.81 \mathrm{~g} ; \mathrm{ZnSO}_{4} \cdot 7$ $\mathrm{H}_{2} \mathrm{O}, 0.222 \mathrm{~g} ; \mathrm{Na}_{2} \mathrm{MoO}_{4} \cdot 2 \mathrm{H}_{2} \mathrm{O}, 0.390 \mathrm{~g} ; \mathrm{CuSO}_{4} \cdot 5 \mathrm{H}_{2} \mathrm{O}, 79 \mathrm{mg}$ and $\mathrm{Co}\left(\mathrm{NO}_{3}\right)_{2}$ . $6 \mathrm{H}_{2} \mathrm{O}, 49.4 \mathrm{mg} \mathrm{l}^{-1}$ ) was used for growth and fatty acid production of both species. However, $\mathrm{NaNO}_{3}$ was omitted from the medium in case of $\mathrm{N}$ free medium experiments. The $\mathrm{pH}$ of all cultures was 7.4.

All cultures were incubated at room temperature of $27 \pm 1^{\circ} \mathrm{C}$ and continuous light using two fluorescent tubes of TL-D $18 \mathrm{~W}$ (snow white extreme cool day light E9, made in Poland) and bubbled with sterilised air.

A colony from the agar cultures of Chlorella sp. and D. quadricaudatus transferred to fresh BG-11 liquid medium contained $\mathrm{NaNO}_{3}$ and leave to grow under the above growth conditions. This culture used as stock culture in next experiments.

Three cultures for each species were grown in fresh BG-11 medium contained $1.5 \mathrm{~g} \mathrm{NaNO}_{3} \mathrm{l}^{-1}$ to measure growth as chlorophyll-a. Specific growth and the maximum growth rates calculated by Equation 1:

$$
\text { specific growth rate; } \mu=\ln (N 1-N 2) /(t 1-t 2),
$$

where $N 1$ and $N 2$ are biomass at time $t 1$ and $t 2$, respectively.

To determine fatty acid composition, certain volumes of the stock culture were inoculated to the fresh medium contained $1.5 \mathrm{~g} \mathrm{NaNO}_{3}{ }^{-1}$. Chlorophyll-a, turbidity and nitrate were measured each three days. After depletion of nitrate from culture suspension, the culture was divided into two new culture flasks. One flask contained fresh medium with $1.5 \mathrm{~g} \mathrm{NaNO}_{3} \mathrm{l}^{-1}$ (diluted culture with $\mathrm{N}$ ) and the other was diluted with $\mathrm{NaNO}_{3}$ free medium (diluted culture without $\mathrm{N}$ ). The algal biomasses were harvested and fatty acid profiles determined at late stationary growth phase (the end of the experiments). All cultures were pure but non-axenic and ran in three replicates.

\section{Measurement of growth and estimation of algal biomass}

The growth of algae measured as chlorophyll-a. Chlorophyll-a measured according to Iwamura et al. (1970) at 653, 666 and $750 \mathrm{~nm}$ using 6800 Double beam UV/Visible Spectrophotometer, Jenway, made in England. 
Growth rate $\left(\mu, \mathrm{d}^{-1}\right)$ were calculated according to Equation 1 (Andersen 2005).

\section{Nitrate concentration determination}

Nitrate concentration in the algal suspension determined according to Cataldo et al. (1975) using spectrophotometer (6405 UV/Visible Spectrophotometer, Jenway, England).

\section{Biomass collection}

The colonies of Desmodesmus quadricaudatus were self-settled by stopped culture aeration for 2 hours then the settled biomass was collected and dried at $30^{\circ} \mathrm{C}$ for 2 days.

For settling of Chlorella cells, alum (Aluminum Sulphate octadecahydrate; $\mathrm{Al}_{2}\left(\mathrm{SO}_{4}\right)_{3} \cdot 18 \mathrm{H}_{2} \mathrm{O}$, molar mass $\left.666.42 \mathrm{~g} \mathrm{~mol}^{-1}\right)$, as a chemical flocculent was added to the culture of Chlorella sp. for settling then the biomass was harvested and dried at $30^{\circ} \mathrm{C}$ for 2 days. The lowest alum concentration that makes the best precipitation of Chlorella sp. was determined by adding $0,1.8$,

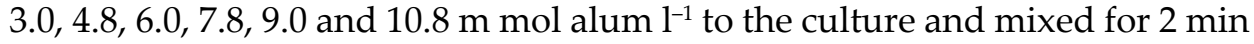
thereafter left to settling.

\section{Oil extraction}

Dried algal biomass ( $2 \mathrm{~g}$ ) were extracted all night in hexane/ether solution $(1 / 1, \mathrm{~V} / \mathrm{V})$ to extract oil. The mixture was kept for $24 \mathrm{~h}$ for settling. This step repeated until the extract became hyaline (Basova 2005). Then the extract was evaporated in vacuum to release hexane and ether solutions (Hossain et al. 2008) using rotary evaporator (Diagonal Condenser-RE300, PTFE/glass liquid pathway for chemical inertness, sparkles induction motor, long life graphite impregnated PTFE vacuum seal, efficient flask and vapour tube ejection system, speed range 20 to $190 \mathrm{rpm}$, Vacuum $1 \mathrm{~mm} \mathrm{Hg}$, made in UK).

\section{Fatty acid analysis}

The extracted oil was converted to fatty acid methyl ester according to Luddy et al. (1960) and measured using gas chromatography (Perkin Elmer Auto system $\mathrm{XL}$ ) equipped with flame ionization detector (FID), fused silica capillary column DB-5 (60 $\mathrm{m} \times 0.32 \mathrm{~mm}$ i.d.). The oven temperature was maintained initially at $150^{\circ} \mathrm{C}$ and programmed from $150{ }^{\circ} \mathrm{C}$ to $240{ }^{\circ} \mathrm{C}$ at rate $3{ }^{\circ} \mathrm{C} / \mathrm{min}$, 
then held at $240{ }^{\circ} \mathrm{C}$ for $30 \mathrm{~min}$. The injector temperature was $230{ }^{\circ} \mathrm{C}$. Detector temperature was $250{ }^{\circ} \mathrm{C}$ and carrier gas was Helium with flow rate of $1 \mathrm{ml}$ $\left.\mathrm{min}^{-1}\right)$. The 3-Nonanone used as standard.

\section{RESULTS}

A strain of Chlorella sp. and Desmodesmus quadricaudatus were isolated, identified and grown in BG-11 medium. The growth of both species was investigated as chlorophyll-a concentration. The cultures entered stationary growth phase after $72 \mathrm{~h}$. The maximum growth rates $\left(\mu_{\max }\right)$ were 3.02 and $2.96 \mathrm{~d}^{-1}$ for Chlorella sp. and D. quadricaudatus, respectively (Fig. 1).

In the experiments for fatty acids production, Chlorella sp. and D. quadricaudatus were grown in culture medium contained $1.5 \mathrm{~g} \mathrm{NaNO}_{3} \mathrm{l}^{-1}$ till nitrate undetected in the culture suspension. Nitrate concentration was undetected in culture suspension by day 6 and day 12 for Chlorella sp. and D. quadricaudatus, respectively (Fig. 2). Then the cultures divided to two equal volumes and diluted by fresh medium. One culture group was grown in culture medium containing $1.5 \mathrm{~g} \mathrm{NaNO}_{3} \mathrm{l}^{-1}$ and the other group in nitrate free medium.

Table 1 recorded the growth of all cultures biomass measured as chlorophyll-a and the changing of growth rates of both species.

Chlorella reached a maximum chlorophyll-a concentration of $10650 \pm 54$ $\mu \mathrm{g} \mathrm{l}^{-1}$ after 12 days of dilution in diluted cultures with $1.5 \mathrm{~g} \mathrm{NaNO}_{3} \mathrm{l}^{-1}$. While D. quadricaudatus reached a maximum chlorophyll-a concentration of $2207 \pm 68$ $\mu \mathrm{g} \mathrm{l}^{-1}$ after 3 days of dilution (Table 1 ).

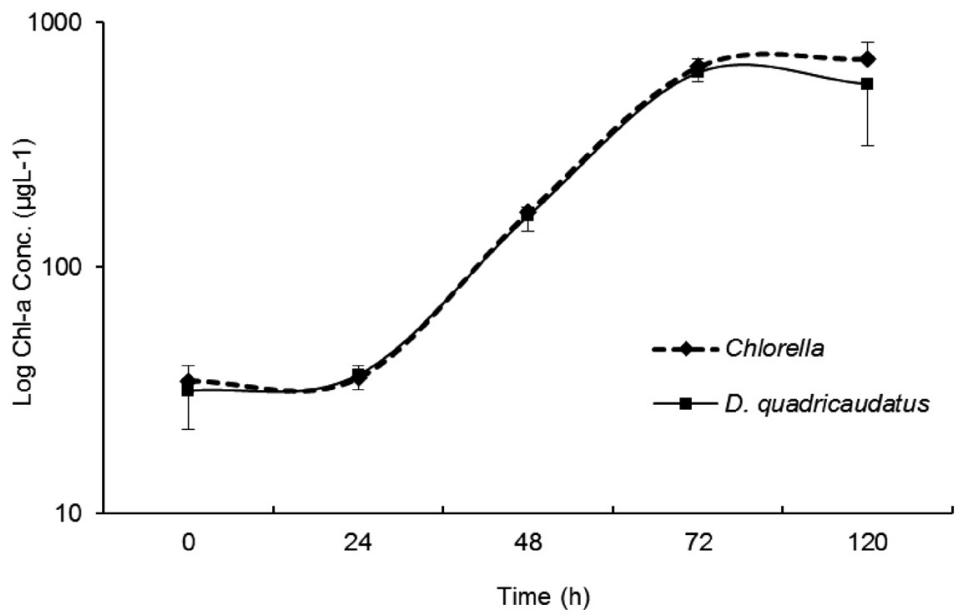

Fig. 1. Growth curve of Chlorella sp. and Desmodesmus quadricaudatus measured as chlorophyll-a at room temperature of $27 \pm 1^{\circ} \mathrm{C}$, with continuous light. Standard error bars for

Chlorella sp. shows in plus direction and for D. quadricaudatus in minus direction 
Table 1

Growth of Chlorella sp. and Desmodesmus quadricaudatus measured as chlorophyll-a ( $\mu \mathrm{g} \mathrm{^{-1 } )}$ at room temperature of $27 \pm 1^{\circ} \mathrm{C}$, with continuous light

\begin{tabular}{|c|c|c|c|c|c|}
\hline \multirow[t]{2}{*}{ Algal species } & \multirow{2}{*}{$\begin{array}{l}\text { Time } \\
\text { (days) }\end{array}$} & \multicolumn{2}{|c|}{ Diluted culture with $\mathrm{N}$} & \multicolumn{2}{|c|}{ Diluted culture without $\mathrm{N}$} \\
\hline & & $\begin{array}{l}\text { Chlorophyll-a } \\
\left(\mu \mathrm{g} \mathrm{l}^{-1}\right)\end{array}$ & $\begin{array}{l}\text { Growth } \\
\text { rate }\left(\mathrm{d}^{-1}\right)\end{array}$ & $\begin{array}{c}\text { Chlorophyll-a } \\
\left(\mu \mathrm{g} \mathrm{l}^{-1}\right)\end{array}$ & $\begin{array}{l}\text { Growth } \\
\text { rate }\left(\mathrm{d}^{-1}\right)\end{array}$ \\
\hline \multirow[t]{6}{*}{ Chlorella sp. } & 0 & $1038.8 \pm 0.0$ & & $1034.5 \pm 10.5$ & \\
\hline & 3 & $5520.8 \pm 94.5$ & 0.56 & $2152.8 \pm 19.2$ & 0.24 \\
\hline & 6 & $8714.2 \pm 47.7$ & 0.15 & $3085.3 \pm 35.0$ & 0.12 \\
\hline & 9 & $9770.5 \pm 54.4$ & 0.04 & $3238.2 \pm 35.5$ & 0.02 \\
\hline & 12 & $10650.5 \pm 53.9$ & 0.03 & $847.8 \pm 9.2$ & -0.45 \\
\hline & 15 & $10268.3 \pm 11.9$ & -0.01 & $838.8 \pm 9.5$ & 0.0 \\
\hline \multirow[t]{5}{*}{ D. quadricaudatus } & 0 & $628.6 \pm 48.8$ & & $630.8 \pm 0.5$ & \\
\hline & 3 & $2207.3 \pm 68.0$ & 0.42 & $682.9 \pm 0.8$ & 0.03 \\
\hline & 6 & $2149.7 \pm 71.3$ & -0.01 & $713.0 \pm 0.5$ & 0.01 \\
\hline & 9 & $1715.2 \pm 11.9$ & -0.08 & $638.7 \pm 19.1$ & -0.04 \\
\hline & 12 & $1639.5 \pm 10.5$ & -0.02 & $1342.9 \pm 34.0$ & 0.25 \\
\hline
\end{tabular}

In diluted cultures of nitrate free medium, Chlorella reach a maximum chlorophyll-a concentration of $3238 \pm 35.5 \mu \mathrm{g} \mathrm{l}^{-1}$ after 9 days of dilution (Table 1). While $D$. quadricaudatus reach a maximum chlorophyll-a concentration of $1343 \pm 34 \mu \mathrm{g} \mathrm{l}^{-1}$ only after 12 days of dilution (Table 1 ). At late stationary phase (last day of the experiments), samples were harvested from all cultures for fatty acids analysis.

The specific growth rates $(\mu)$ of both algae were calculated as chlorophyll-a concentration in all cultures. The specific growth rates (after 3 days)

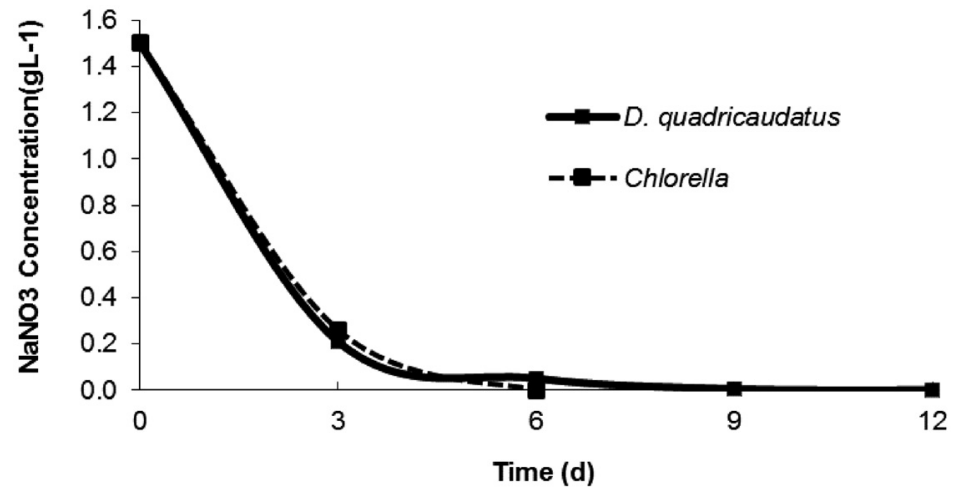

Fig. 2. Nitrate concentration in Chlorella sp. and Desmodesmus quadricaudatus cultures measured at room temperature of $27 \pm 1^{\circ} \mathrm{C}$, with continuous light 


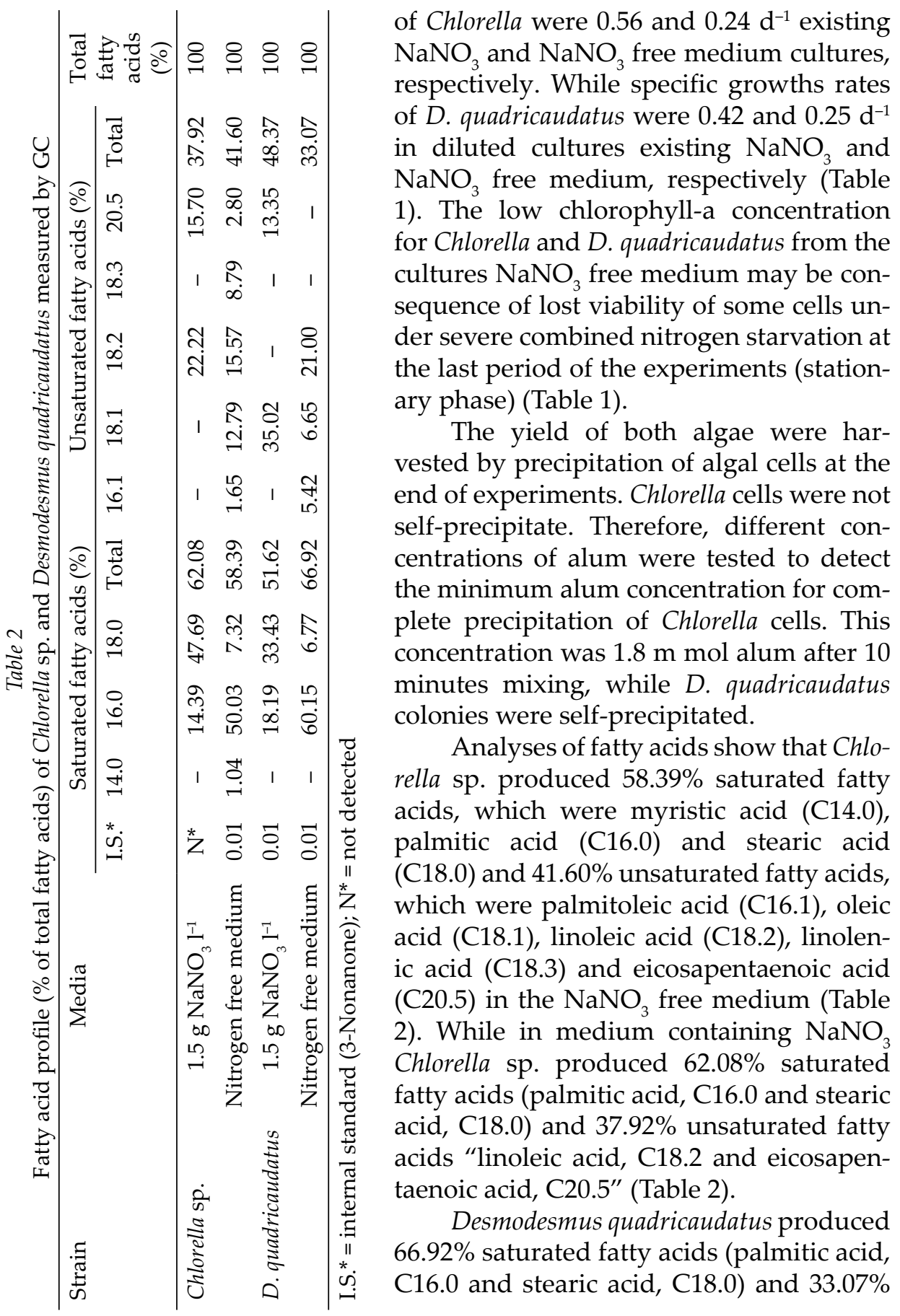


unsaturated fatty acids (palmitoleic acid, C16.1, oleic acid, C18.1 and linoleic acid, C18.2) in $\mathrm{NaNO}_{3}$ free medium. While in medium containing $\mathrm{NaNO}_{3}$ produced $51.62 \%$ saturated fatty acids (palmitic acid, C16.0 and stearic acid, C18.0) and 48.37\% unsaturated fatty acids "oleic acid, C18.1 and eicosapentaenoic acid, C20.5" (Table 2). So the results in Table 3 show that the type and amount of fatty acids more or less affected by the mode of nitrogen supply.

Figure 3 shows the fatty acid profile as saturated fatty acids (SFA), monounsaturated fatty acids (MUFA) and polyunsaturated fatty acids (PUFA) of Chlorella sp. and D. quadricaudatus grown in media with or without $\mathrm{NaNO}_{3}$.

\section{DISCUSSION}

The choice of microalgae for fatty acids profiles and for biofuel production requires a balance between species that grow quickly against those, which produce oil in large quantities. Therefore, Chlorella sp. and Desmodesmus quadricaudatus were chosen in this investigation, where both species have high maximum growth rate of 3.02 and $2.96 \mathrm{~d}^{-1}$, respectively. These maximum growth rates are significant factor for algal mass production. Shafik (1991) recorded a maximum growth rate for Scenedesmus spinosus (currently, Desmodes-

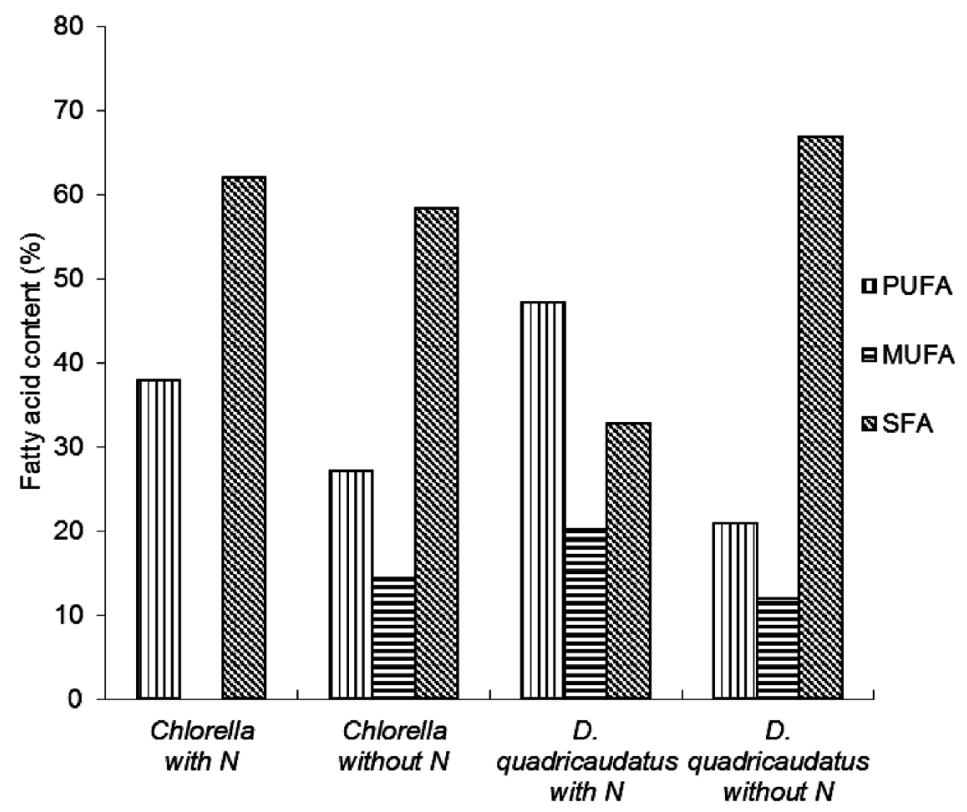

Fig. 3. Fatty acid profile of Desmodesmus quadricaudatus and Chlorella sp. grown in BG-11 medium contained $1.5 \mathrm{~g} \mathrm{NaNO}_{3} \mathrm{l}^{-1}$ or in nitrogen free medium. SFA = saturated fatty acids; MUFA = monounsaturated fatty acids; PUFA = polyunsaturated fatty acids 
mus spinosus) of $3.0 \mathrm{~d}^{-1}$, which is close to the obtained data. High maximum growth rate is an indication for favourable growth conditions. Jena et al. (2012) obtained that the specific growth rate for both Chlorella and Scenedesmus sp. was $0.38 \mathrm{~d}^{-1}$. Further, given that most oil is produced during a "starvation" or "stress" phase, successful fatty acid production will require species that can be reliably manipulated, is tolerant of a range of environmental perturbations - natural and operator induced - and is able to "recover" from these alterations and continue growing (Jena et al. 2012). It is important to possess data on how the nitrogen starvation can influence the profile of produced fatty acids so the various fatty acid profiles of the different sources can be used for production, such as biodiesel fuel.

One of the most important processes for studying the fatty acid profiles is the harvesting of algal yield. Algae can be harvested using micro-screens, by centrifugation, or by flocculation. Froth flotation is another method to harvest algae. Interrupting the carbon dioxide supply to an algal culture system could cause algae to flocculate on its own, which is called "autoflocculation". Harvesting by sedimentation (bioflocculation) was really promising, but it was strain specific and was increased by $\mathrm{N}$ limitation (Sheehan et al. 1998). Harvesting capability is an important feature of microalgae fatty acids analysis (Christenson and Sims 2011, Scholz et al. 2011). Park et al. (2011) showed that many microalgae settle under adverse conditions, and this could be tested under small-scale conditions. Some strains of Chlorella did not settle (Sheehan et al. 1998). Here the tested Chlorella sp. was not self-precipitated. Therefore, different concentrations of alum were used to detect the lowest alum concentration that precipitate most of Chlorella cells. This concentration was $1.8 \mathrm{~m}$ mol $\mathrm{Al}_{2}\left(\mathrm{SO}_{4}\right)_{3} \cdot 18 \mathrm{H}_{2} \mathrm{O}$. However, D. quadricaudatus was self-precipitated and easily harvested.

Basova (2005) showed the major fatty acids of different algal groups and reported that the lipids of many microalgae species are rich in polyunsaturated fatty acids (PUFAs).

Jena et al. (2012) obtained that Scenedesmus sp. produced 36.5\% saturated fatty acid and $63.5 \%$ unsaturated fatty acid. Scenedesmus sp. contained high amount of palmitic acid (16:0, 30.3\%) and the unsaturated fatty acids were represented by linoleic acid (C18:2, 21.1\%) and oleic acid (18:1, 17.5\%). Other long-chain PUFAs are present in small amount. These properties make Scenedesmus sp. suitable for biodiesel production. Rodolfi et al. (2009) concluded that culturing and environmental conditions affect the productivity of algae, lipid yield and fatty acid compositions. In a pilot study of Chlorella sp. the high growth rates could be achieved by increasing nitrogen concentrations, while lipid accumulation could be achieved by nitrogen starvation. Basova (2005) reported that Chlorella sp. produced $34.0 \%$ saturated fatty acid and $66.0 \%$ un- 
Table 3

Comparison of fatty acid composition (\% of total fatty acids) of some microalgal strain grown at stationary phase

\begin{tabular}{|c|c|c|c|c|c|c|}
\hline Fatty acids & C1 & S1 & $\mathrm{C} 2+\mathrm{N}$ & C3-N & $D 1+\mathrm{N}$ & D2-N \\
\hline 12.0 & 0.3 & - & - & - & - & - \\
\hline 14.0 & 0.9 & 0.7 & - & 1.04 & - & - \\
\hline 15.0 & 0.3 & 0.3 & - & - & - & - \\
\hline 16.0 & 24.5 & 30.3 & 14.39 & 50.03 & 18.19 & 60.15 \\
\hline 16.1 & 4.9 & 6.5 & - & 1.65 & - & 5.42 \\
\hline 16.2 & 1.3 & 5.7 & - & - & - & - \\
\hline 16.3 & - & - & - & - & - & - \\
\hline 16.4 & - & - & - & - & - & - \\
\hline 17.0 & 2.1 & 2.6 & - & - & - & - \\
\hline 17.1 & 10.0 & 2.7 & - & - & - & - \\
\hline 18.0 & 2.5 & 1.2 & 47.69 & 7.32 & 33.43 & 6.77 \\
\hline 18.1 & 15.1 & 17.5 & - & 12.79 & 35.02 & 6.65 \\
\hline 18.2 & 5.7 & 21.1 & 22.22 & 15.57 & - & 21.0 \\
\hline 18.3 & 26.3 & 9.2 & - & 8.79 & - & - \\
\hline 18.4 & - & - & - & - & - & - \\
\hline 20.0 & 0.4 & 0.1 & - & - & - & - \\
\hline 20.1 & 0.4 & - & - & - & - & - \\
\hline 20.2 & 0.3 & 0.3 & - & - & - & - \\
\hline 20.3 & 0.3 & 0.1 & - & - & - & - \\
\hline 20.4 & - & - & - & - & - & - \\
\hline 20.5 & 1.1 & 0.8 & 15.70 & 2.80 & 13.35 & - \\
\hline 21.0 & 1.1 & - & - & - & - & - \\
\hline 22.0 & 1.1 & 0.6 & - & - & - & - \\
\hline 22.1 & 0.6 & - & - & - & - & - \\
\hline 24.0 & 0.8 & 0.3 & - & - & - & - \\
\hline SFA & 34.0 & 36.5 & 62.08 & 58.39 & 51.62 & 66.92 \\
\hline USFA & 66.0 & 63.5 & 37.92 & 41.60 & 48.37 & 33.07 \\
\hline
\end{tabular}

C1, S1 presented Chlorella sp. and Scenedesmus sp. after Jena et al. (2012), in the present study, $C 2+\mathrm{N}$ indicates Chlorella sp. grown in culture contain $1.5 \mathrm{~g} \mathrm{NaNO}_{3}$ $1^{-1}, C 3-\mathrm{N}$ indicates Chlorella sp. grown in nitrogen free medium, $D 1+\mathrm{N}$ indicates Desmodesmus quadricaudatus grown in culture contain $1.5 \mathrm{~g} \mathrm{NaNO}_{3} \mathrm{1}^{-1}$ and $D 2-\mathrm{N}$ indicates $D$. quadricaudatus grown in nitrogen free medium 
saturated fatty acid, higher amount of UFA was present among which PUFA content is $35 \%$. The unsaturated fatty acids, linolenic acid (18.3) was the most dominant fatty acid $(26.3 \%)$ besides the PUFA, oleic acid $(18: 1,15.1 \%)$ and palmitic acid (16:0, 24.5\%) were the principal fatty acids in Chlorella sp. (Jena et al. 2012) (Table 3).

Thomas et al. (1984) recorded that at low concentration of nitrogen Chlorella synthesised saturated (16:0) and monounsaturated (18:1) fatty acids, whereas at high nitrogen concentrations the 16:2, 16:3, 16:4 and 18:2 fatty acids predominated. Chlorella sp. is an oleaginous alga, that has a potential application, is currently used at pilot experimental level for biodiesel production, is commercially produced and available in large quantities.

Lee et al. (2011) stated that saturated and unsaturated fatty acids like palmitic acid (C16:0), stearic acid (C18:0), oleic acid (C18:1), linoleic acid (C18:2), and linolenic acid (C18:3) are common fatty acids for biodiesel production. Thomas et al. (1984) reported that significant fatty acids used for biodiesel production, include saturated fatty acids and polyunsaturated fatty acids (PUFAs), such as C14:0, C16:0, C16:1, C18:0, C18:1, C18:2, C18:3 fatty acids. In our results, Chlorella sp. in $\mathrm{NaNO}_{3}$ free media tended to produce a diverse fatty acid pattern consisting of saturated (C14.0, C16.0 and C18.0) and unsaturated fatty acids (C16.1, C18.1, C18.2, C18.3 and C20.5). D. quadricaudatus produced unsaturated fatty acids (C16.1, C18.1 and C18.2) and saturated fatty acids, which were represented by (C16.0 and C18.0) in $\mathrm{NaNO}_{3}$ free media (Tables 2, 3). Accordingly, both species that isolated from Egyptian water body may be suitable for biodiesel production, where it contains all these types of fatty acids.

Acknowledgements - The authors would like to extend their sincere appreciation to the Distinguished Scientist Fellowship Program of Egypt for funding this research. Also, the authors would like to extend their sincere appreciation to the Deanship of Scientific Research at King Saud University for its funding this research through the Research Group no. (RG-1436-242).

\section{REFERENCES}

Andersen, R. A. (2005): Algal culturing techniques. 1st ed. - Academic Press, London, 596 pp. Barsanti, L. and Gualtieri, P. (2006): Algae: anatomy, biochemistry and biotechnology. 2nd ed. Taylor and Francis Group, 352 pp.

Basova, M. M. (2005): Fatty acid composition of lipids in microalgae. - Int. J. Algae 7: 33-57. doi: 10.1615/InterJAlgae.v7.i1.30

Cataldo, D. A., Maroona, M., Schradera, L. E. and Youngsa, V. L. (1975): Rapid colorimetric determination of nitrate in plant tissues by nitration of salicylic acid. - Commun. Soil Sci. Plant Anal. 6: 71-80. doi: 10.1080/00103627509366547 
Chisti, Y. (2007): Biodiesel from microalgae. - Biotechnol. Adv. 25: 294-306. doi: 10.1016/j. biotechadv.2007.02.001

Christenson, L. and Sims, R. (2011): Production and harvesting of microalgae for wastewater treatment, biofuels, and bioproducts. - Biotechnol. Adv. 29: 686-702. doi: 10.1016/j. biotechadv.2011.05.015

Dayananda, C., Sarada, R., Kumar, V. and Ravishankar, G. A. (2007): Isolation, characterization of hydrocarbon producing green microalgae Botryococcus braunii from Indian fresh-water bodies. - Electron J. Biotechnol. 10: 78-91. doi: 10.2225/vol10-issue1fulltext-11

Hossain, A. B. M., Salleh, A., Boyce, A. N., Chowdhury, P. and Naqiuddin, M. (2008): Biodiesel fuel production from algae as renewable energy. - Am. J. Biochem. Biotechnol. 4: 250-254. doi: 10.3844/ajbbsp.2008.250.254

Hsieh, C. H. and Wu, W. T. (2009): Cultivation of microalgae for oil production with a cultivation strategy of urea limitation. - Bioresour. Technol. 100: 3921-3926. doi: 10.1016/j. biortech.2009.03.019

$\mathrm{Hu}$, Q., Sommerfeld, M., Jarvis, E., Ghirardi, M., Posewitz, M., Seibert, M. and Darzins, A. (2008): Microalgal triacyl-glycerols as feedstocks for biofuel production: perspectives and advances. - Plant J. 54: 621-639. doi: 10.1111/j.1365-313X.2008.03492.x

Illman, A. M., Scragg, A. H. and Shales, S. W. (2000): Increase in Chlorella strains calorific values when grown in low nitrogen medium. - Enzym. Microb. Technol. 27: 631-635. doi: 10.1016/S0141-0229(00)00266-0

Iwamura, T., Nagai, H. and Ichimura, S. (1970): Improved methods for determining contents of chlorophyll, protein, ribonucleic acid, and deoxyribonucleic acid in planktonic populations. - Int. Res. Ges. Hydrobiol. 55: 131-147. doi: 10.1002/iroh.19700550106

Jena, J., Nayak, M., Panda, H. S., Pradhan, N., Sarika, C., Panda, P. K., Rao, B., Prasad, B. N. and Sukla, L. B. (2012): Microalgae of Odisha coast as a potential source for biodiesel production. - World Environ. 2: 11-16. doi: 10.1002/iroh.19700550106

Kapdan, I. K. and Kargi, F. (2006): Bio-hydrogen production from waste materials. - Enzyme Microb. Tech. 38: 569-582. doi: 10.1016/j.enzmictec.2005.09.015

Kenesi, G., Shafik, H. M., Kovács, A. W., Herodek, S. and Présing, M. (2009): Effect of nitrogen forms on growth, cell composition and $\mathrm{N}_{2}$ fixation of Cylindrospermopsis raciborskii in phosphorus-limited chemostat cultures. - Hydrobiologia 623: 191-202. doi: 10.1007/s10750-008-9657-9

Lee, S. J., Go, S., Jeong, G. T. and Kim, S. K. (2011): Oil production from five marine microalgae for the production of biodiesel. - Biotechnol. Bioprocess Eng. 16: 561-566. doi: 10.1007/s12257-010-0360-0

Li, Y., Horseman, M., Wang, B., Wu, N. and Lan, C. Q. (2008): Effects of nitrogen sources on cell growth and lipid accumulation of green alga Neochloris oleoabundans. - Appl. Microbiol. Biotechnol. 81: 629-636. doi: 10.1007/s00253-008-1681-1

Luddy, F. E., Beerford, R. A. and Riemenschneider, R. W. (1960): Direct conversion of lipid component to their fatty acid methyl ester. - J. Am. Oil Chem. Soc. 37: 447-451. doi: 10.1007/BF02631205

Mata, T. M., Martins, A. A. and Caetano, N. S. (2010): Microalgae for biodiesel production and other applications: a review. - Renew Sust. Energ. Rev. 14: 217-232. doi: 10.1016/j. rser.2009.07.020

Meier, R. L. (1955): Biological cycles in the transformation of solar energy into useful fuels. - In: Daniels, F. and Duffie, J. A. (eds): Solar energy research. University of Wisconsin Press, Madison, WI, USA, pp. 179-183. 
Park, J. B. K., Craggs, R. J. and Shilton, A. N. (2011): Recycling algae to improve species control and harvest efficiency from a high rate algal pond. - Water Res. 45: 6637-6649. doi: 10.1016/j.watres.2011.09.042

Paulson, N. D. and Ginder, R. D. (2007): The growth and direction of biodiesel industry in the United States. - Center for Agricultural and Rural Development, Iowa State University, IA, USA, 3 pp.

Rodolfi, L., Chini, Z. G., Bassi, N., Padovani, G., Biondi, N., Bonini, G. and Tredici, M. R. (2009): Microalgae for oil: strain selection, induction of lipid synthesis and outdoor mass cultivation in a low-cost photobioreactor. - Biotechnol. Bioeng. 102: 100-112. doi: 10.1002/bit.22033

Scholz, M., Hoshino, T., Johnson, D., Riley, M. R. and Cuello, J. (2011): Flocculation of walldeficient cells of Chlamydomonas reinhardtii mutant cw15 by calcium and methanol. - Biomass Bioenerg. 35: 4835-4840. doi: 10.1016/j.biombioe.2011.08.020

Schuchard, U., Serchelia, R. and Vargas, R. (1998): Transesterification of vegetable oils: a review. - J. Braz. Chem. Soc. 9: 199-210.

Scragg, A. H., Illman, A. M., Carden, A. and Shales, S. W. (2002): Growth of microalgae with increased calorific values in a tubular bioreactor. - Biomass Bioenerg. 23: 67-73. doi: 10.1016/S0961-9534(02)00028-4

Shafik, H. M. (1991): Growth, nutrient uptake and competition of algae of Lake Balaton in flowthrough cultures. - Hungarian Academy of Sciences, Hungary, 121 pp. (unpubl. dissert., mscr.).

Shafik, H. M. (2003): Morphological characteristics of Cylindrospermopsis raciborskii (Wołoszyńska) Seenayya et Subba Raju in laboratory cultures. - Acta. Biol. Hung. 54: 121-136. doi: 10.1556/ABiol.54.2003.1.13

Sheehan, J., Dunahay, T., Benemann, J. and Roessler, P. (1998): A look back at the U.S. Department of Energy's Aquatic Species Program: biodiesel from Algae. - National Renewable Energy Laboratory, Golden, CO, USA, $296 \mathrm{pp}$.

Shifrin, N. S. and Chisholm, S. W. (1981): Phytoplankton lipids: interspecific differences and effects of nitrate, silicate and light-dark cycles. - J. Phycol. 17: 374-384. doi: 10.1111/j.0022-3646.1981.00374.x

Smith, T. E. (2010): Revised list of algae from Arkansas, U.S.A. and new additions. - Int. J. Algae. 12: 230-256. doi: 10.1615/InterJAlgae.v12.i3.30

Thomas, F. R. (2006): Algae for liquid fuel production. - Permaculture Activist. 59: 1-2.

Thomas, W. H., Tornabene, T. G. and Weissman, J. (1984): Screening for lipid yielding microalgae: activities for 1983. - Solar Energy Research Institute, Golden, Colorado, USA, $45 \mathrm{pp}$.

Tyagi, O. S., Atray, N., Kumar, B. and Datta, A. (2010): Production, characterization and development of standards for biodiesel: a review. - J. Metrology Soc. India 25: 197-218. 